\title{
Full genomic characterization of a porcine rotavirus strain detected in an asymptomatic piglet in Accra, Ghana
}

Samuel C. B. Stubbs', Osbourne Quaye $2^{2 *}$, Maame Ekua Acquah², Samuel Mawuli Adadey², lain R. L. Kean ${ }^{1}$, Srishti Gupta ${ }^{1}$ and Barbara A. Blacklaws ${ }^{1}$

\begin{abstract}
Background: The introduction of rotavirus A vaccination across the developing world has not proved to be as efficacious as first hoped. One cause of vaccine failure may be infection by zoonotic rotaviruses that are very variable antigenically from the vaccine strain. However, there is a lack of genomic information about the circulating rotavirus $A$ strains in farm animals in the developing world that may be a source of infection for humans. We therefore screened farms close to Accra, Ghana for animals sub-clinically infected with rotavirus A and then sequenced the virus found in one of these samples.

Results: $6.1 \%$ of clinically normal cows and pigs tested were found to be Rotavirus A virus antigen positive in the faeces. A subset of these (33.3\%) were also positive for virus RNA. The most consistently positive pig sample was taken forward for metagenomic sequencing. This gave full sequence for all open reading frames except segment 5 (NSP1), which is missing a single base at the 5' end. The virus infecting this pig had genome constellation G5-P[7]-I5-R1-C1-M1A8-N1-T7-E1-H1, a known porcine genotype constellation.

Conclusions: Farm animals carry rotavirus A infection sub-clinically at low frequency. Although the rotavirus A genotype discovered here has a pig-like genome constellation, a number of the segments most closely resembled those isolated from humans in suspected cases of zoonotic transmission. Therefore, such viruses may be a source of variable gene segments for re-assortment with other viruses to cause vaccine breakdown. It is recommended that further human and pig strains are characterized in West Africa, to better understand this dynamic.
\end{abstract}

Keywords: Rotavirus A, Full genome sequence constellation, Pig, Porcine, Ghana

\section{Background}

Group A rotaviruses (RVA) (family Reoviridae, genus Rotavirus) are the single most common etiology of acute gastroenteritis (AGE) among the young of both humans and domestic animals worldwide $[1,2]$. The rotavirus genome is composed of 11 double-stranded RNA segments which encode six structural and five or six nonstructural proteins. Currently, RVA strains are classified based on the open reading frame sequences of all the 11 genes as Gx-P[x]-Ix-Rx-Cx-Mx-Ax-Nx-Tx-Ex-Hx [3]. To date, at least 36 G-types, 51 P-types, 26 I-types, $22 \mathrm{R}$ -

\footnotetext{
* Correspondence: oquaye@ug.edu.gh

${ }^{2}$ West African Centre for Cell Biology of Infectious Pathogens (WACCBIP), Department of Biochemistry, Cell and Molecular Biology, University of Ghana, Volta Road, P. O. Box LG 54, Legon, Accra, Ghana
}

Full list of author information is available at the end of the article types, 20 C-types, $20 \mathrm{M}$-types, 31 A-types, $22 \mathrm{~N}$-types, $22 \mathrm{~T}$-types, $27 \mathrm{E}$-types, and $22 \mathrm{H}$-types have been detected (https://rega.kuleuven.be/cev/viralmetagenomics/ virus-classification/newgenotypes). Porcine RVA strains vary in the $G$ and $P$ types detected, but commonly have a I5-R1-C1-M1-A8-N1-T7-E1-H1 genetic backbone; although $\mathrm{A} 1, \mathrm{~T} 1$ and occasional $\mathrm{C} 2$ genotypes have also been seen in porcine isolates [4].

The distribution of RVA strains found in humans and animals strongly supports host species barriers and restriction [5]. However, the detection of genotypes in humans that have been previously found in animals suggests that RVA is capable of undergoing adaptions permitting interspecies transmission [6, 7]. Animal and avian species have therefore become potential reservoirs

(c) The Author(s). 2020 Open Access This article is distributed under the terms of the Creative Commons Attribution 4.0 International License (http://creativecommons.org/licenses/by/4.0/), which permits unrestricted use, distribution, and reproduction in any medium, provided you give appropriate credit to the original author(s) and the source, provide a link to the Creative Commons license, and indicate if changes were made. The Creative Commons Public Domain Dedication waiver (http://creativecommons.org/publicdomain/zero/1.0/) applies to the data made available in this article, unless otherwise stated. 
of rotaviruses that can infect humans. Unusual rotavirus strains in humans are suspected to have evolved either as a single virus infection, or from genetic reassortment between human, animal and avian species as a result of co-infection [6, 7]. Therefore, there is a need to perform animal rotavirus surveillance and monitoring of the role of animal rotaviruses as a potential genetic reservoir for emerging rotavirus strains that are pathogenic to humans.

In Ghana, as in many developing countries, there is close contact between humans and domestic and/or farm animals. In various communities in developing countries, wild animals are also used as sources of meat/ protein and thus come into direct contact with humans. These interactions could be prime causes of zoonotic transmission and result in possible genetic reassortment, ultimately leading to ineffective vaccination regimes. There are no sequence data for veterinary-associated RVA strains from Ghana apart from a limited number of incomplete sequences from bats. In this study, we report a full genome characterization of a porcine Group A rotavirus strain that was detected in an asymptomatic pig on a swine farm in Accra, Ghana. This genomic sequence contributes to the database of circulating rotavirus strains in sub-Saharan Africa.

\section{Results}

\section{Detection of rotavirus positive samples}

Of the normal faecal samples taken from 445 pigs and cattle, 27 were positive for rotavirus antigen using the Rotavirus Test Kit (of which 3 were from cattle [1.4\% cattle samples], 24 from pigs [10.4\% pig samples]), 6 of the 27 antigen-positive samples also tested positive for the presence of rotavirus RNA by real-time RT-PCR targeting the NSP3 gene, and a further 3 were positive for VP6 RNA using an RVA specific assay; only one of these samples was from cattle. Sample 14 from a pig gave the most consistent results with strong PCR products. The VP6 PCR product from this sample was Sanger sequenced and found to have the closest nucleotide sequence homology to an RVA I5 genotype strain by BLASTn. In order to further characterize the genome of the rotavirus present, this sample was subjected to metagenomic sequencing.

\section{Metagenomic sequencing}

We next generated near complete sequence for all genomic segments of the RVA in sample (called strain below) 14 (Table 1). The strain 14 segments were genotyped using the RotaC v2.0 web tool [8] (Table 2), which gave a constellation of G5-P[7]-I5-R1-C1-M1-A8-N1-T7-E1-H1. This GX-P[X]-I5-R1-C1-M1-A8-N1-T7-E1-H1 genotype constellation was identical to previously described porcine RVA strains from Belgium, Thailand and Italy [4]. In particular, the genome segments I5, A8 and T7 are associated with porcine RVA strains (Table 2) $[10,15,17,18$ 24], but have also been detected in strains isolated from suspected cases of pig-human transmission, such as KisB332, BE2001, and NT0073. In comparison, human RVA strains from West Africa largely resembled the Walike reference genotype of GX-P[X]-I1-R1-C1-M1-A1-N1T1-E1-H1, although one of these (Ghan-005), also had a DS-1-like I2 segment (Table 2) [25].

BLASTn analysis of the individual segments revealed 89-98\% nucleotide similarity to the closest existing sequences in the GenBank nucleotide database (Table 1). The sequences with the greatest similarity to strain 14 segments included isolates from both pigs and humans, and the majority of these sequences $(17 / 22)$ originated from countries in Asia. For 4 of the segments (VP4, VP6, NSP4 and NSP5), the matches with the greatest identity were exclusively of porcine origin. The VP2, VP3, NSP1 and NSP2 segments displayed similarity to a mixture of porcine, human and giant panda strains. The VP7, VP1, NSP1, and NSP3 segments most closely resembled strains that had been isolated from humans, originating from China, Taiwan, Vietnam and Belgium.

\section{Phylogenetic analysis}

Phylogenetic analysis of each genomic segment was performed against porcine RVA strains and African strains of human origin retrieved from GenBank. We also included the three most closely related RVA strain segments, as identified by BLASTn, regardless of origin. Clades containing large clusters of closely related or identical sequences were pruned to show representative viral strains.

(i.) Outer capsid proteins VP7 and VP4: Segment 9 (VP7) of strain 14 clustered within the genotype G5 clade, which predominantly consisted of strains of porcine origin (Fig. 1). However, the strain 14 segment formed part of a smaller clade within this genotype, which contained sequences derived from both pig and human. The closest related sequences to the strain 14 segment were two human RVA strains isolated from patients in China in 2000 [9] (Table 1). However, the predominance of porcine strains in this clade suggests that these human infections were of zoonotic origin.

The nucleotide sequence of strain 14 segment 4 (VP4) was most homologous to two porcine strains from Australia and Korea isolated in 1986 and 2006 respectively (Table 1) [12,13], although shared identity was only $89 \%$, suggesting these strains were not close relatives. Strain 14 VP4 sits within the $\mathrm{P}$ [7] clade which is derived from only pig isolates from a variety of global sources (Fig. 2) suggesting it is a segment with a porcine lineage. 
Table 1 RVA segment genotypes and closest homologues in GenBank

\begin{tabular}{|c|c|c|c|c|c|c|}
\hline Protein & $\begin{array}{l}\text { Genomic } \\
\text { Segment } \\
\left(b p^{a}\right)\end{array}$ & $\begin{array}{l}\text { Genome } \\
\text { Coverage }^{b}\end{array}$ & Genotype & $\begin{array}{l}\text { Closest match in GenBank } \\
\% \text { nucleotide identity, name }\end{array}$ & Reference & $\begin{array}{l}\text { Percentage identity cut-off values between } \\
\text { genotypes [3] }\end{array}$ \\
\hline \multirow[t]{2}{*}{ VP7 } & $9(1062)$ & $1-1062$ & G5 & $\begin{array}{l}\text { 96\%, RVA/Human-wt/CHN/LL4260/ } \\
\text { 2000/G5P[6] }\end{array}$ & [9] & 80 \\
\hline & & & & $\begin{array}{l}\text { 96\%, RVA/Human-wt/CHN/LL3354/ } \\
\text { 2000/G5P[6] }\end{array}$ & [9] & \\
\hline \multirow[t]{2}{*}{ VP4 } & 4 (2359) & $1-2355$ & $P[7]$ & $\begin{array}{l}\text { 89\%, RVA/Pig-tc/AUS/TFR-41/1986/ } \\
\text { G5P[9] }\end{array}$ & [12] & 80 \\
\hline & & & & $\begin{array}{l}\text { 89\%, RVA/Pig-tc/KOR/174-1/2006/ } \\
\text { G8P[7] }\end{array}$ & [13] & \\
\hline \multirow[t]{2}{*}{ VP6 } & $6(1356)$ & $1-1350$ & 15 & $\begin{array}{l}\text { 98\%, RVA/Pig-wt/CHN/DZ-1/2013/ } \\
\text { G5P[X] }\end{array}$ & ds & 85 \\
\hline & & & & $\begin{array}{l}\text { 96\%, RVA/Pig-wt/CHN/WF-5-1/2014/ } \\
\text { G5P[X] }\end{array}$ & ds & \\
\hline \multirow[t]{2}{*}{ VP1 } & 1 (3302) & $1-3292$ & R1 & $\begin{array}{l}\text { 94\%, RVA/Human-wt/TWN/07-96 s1118/ } \\
\text { 2007/G9P[19] }\end{array}$ & [10] & 83 \\
\hline & & & & $\begin{array}{l}\text { 93\%, RVA/Pig-wt/TWN/2-3/2015/ } \\
\text { G9P[13] }\end{array}$ & [10] & \\
\hline \multirow[t]{2}{*}{ VP2 } & $2(2717)$ & $1-2717$ & $\mathrm{C} 1$ & $\begin{array}{l}\text { 94\%, RVA/Pig-wt/CHN/JL01/2017/ } \\
\text { GXP[17] }\end{array}$ & ds & 84 \\
\hline & & & & $\begin{array}{l}\text { 88\%, RVA/Human-wt/HUN/BP271/2000/ } \\
\text { G4P[6] }\end{array}$ & [11] & \\
\hline \multirow[t]{2}{*}{ VP3 } & $3(2591)$ & $22-2574$ & M1 & $\begin{array}{l}\text { 95\%, RVA/Giant_Panda-tc/CHN/CH-1/ } \\
\text { 2008/G1P[7] }\end{array}$ & [14] & 81 \\
\hline & & & & $\begin{array}{l}\text { 94\%, RVA/Human-wt/CHN/LL3354/ } \\
\text { 2000/G5P[6] }\end{array}$ & [9] & \\
\hline \multirow[t]{2}{*}{ NSP1 } & $5(1567)$ & $13-1522$ & A8 & $\begin{array}{l}\text { 98\%, RVA/Human-tc/NNM/NT0042/ } \\
\text { 2007/G4P[6] }\end{array}$ & [15] & 79 \\
\hline & & & & $\begin{array}{l}\text { 95\%, RVA/Pig-wt/NNM/14226_39/2012/ } \\
\text { G4P[6] }\end{array}$ & [16] & \\
\hline \multirow[t]{2}{*}{ NSP2 } & 8 (1059) & 18-1046 & N1 & $\begin{array}{l}\text { 96\%, RVA/Pig-wt/TWN/3-17/2015/ } \\
\text { G9P[23] }\end{array}$ & [10] & 85 \\
\hline & & & & $\begin{array}{l}\text { 96\%, RVA/Human-wt/TWN/07-96 s1118/ } \\
\text { 2007/G9P[19] }\end{array}$ & [10] & \\
\hline \multirow[t]{2}{*}{ NSP3 } & 7 (1076) & 17-1076 & $\mathrm{T7}$ & $\begin{array}{l}\text { 95\%, RVA/Human-wt/BEL/BE2001/2009/ } \\
\text { G9P[6] }\end{array}$ & [17] & 85 \\
\hline & & & & $\begin{array}{l}\text { 94\%, RVA/Human-wt/COD/KisB332/ } \\
\text { 2008/G4P[6] }\end{array}$ & [18] & \\
\hline \multirow[t]{2}{*}{ NSP4 } & $10(750)$ & $16-741$ & E1 & $\begin{array}{l}\text { 98\%, RVA/Pig-wt/CHN/LLP48/2008/ } \\
\text { G9P[6] }\end{array}$ & ds & 85 \\
\hline & & & & $\begin{array}{l}\text { 98\%, RVA/Pig-wt/CHN/HLJ/15/1/2015/ } \\
\text { G4P[23] }\end{array}$ & ds & \\
\hline \multirow[t]{2}{*}{ NSP5 } & $11(663)$ & $12-639$ & $\mathrm{H} 1$ & 98\%, RVA/Pig-wt/USA/OK.5.68/2008 c & ds & 91 \\
\hline & & & & $\begin{array}{l}\text { 98\%, RVA/Pig-wt/CHN/NMTL/2008/ } \\
\text { G9P[23] }\end{array}$ & [19] & \\
\hline
\end{tabular}

\footnotetext{
ds direct submission
}

${ }^{\mathrm{a}}$ Reference sequence length

${ }^{b}$ Sequences were aligned against the reference genotypes to determine segment coverage

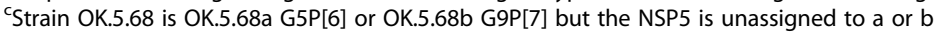

(ii.) Inner capsid protein (VP6): Segment 6 (VP6) of strain 14 clustered within the I5 clade, but formed a small, distinct outgroup with three Chinese isolates from 2013/14 (Fig. 3). The Chinese strains were all isolated by the same group (direct submissions to
GenBank) so are likely to be from the same region. The I 5 clade is dominated by porcine isolates as expected [4] with one human isolate shown, suggesting a porcine lineage for this genomic segment in strain 14 . 
Table 2 Genotype constellations of RVA strain 14, reference sequences, and the most homologous strains in GenBank

\begin{tabular}{|c|c|c|c|c|c|c|c|c|c|c|c|c|}
\hline Strain & VP7 & VP4 & VP6 & VP1 & VP2 & VP3 & NSP1 & NSP2 & NSP3 & NSP4 & NSP5 & Reference \\
\hline RVA/Human-tc/USA/Wa/1974/G1P1A[8] & G1 & $\mathrm{P}[8]$ & II & R1 & $\mathrm{C} 1$ & M1 & $\mathrm{A} 1$ & N1 & $\mathrm{T} 1$ & E1 & $\mathrm{H} 1$ & [3] \\
\hline RVA/Human-tc/USA/DS-1/1976/G2P[4] & G2 & $\mathrm{P}[4]$ & I2 & $\mathrm{R} 2$ & $\mathrm{C} 2$ & M2 & $\mathrm{A} 2$ & $\mathrm{~N} 2$ & $\mathrm{~T} 2$ & E2 & $\mathrm{H} 2$ & [3] \\
\hline RVA/Pig-tc/USA/Gottfried/1975/G4P[6] & G4 & $\mathrm{P}[6]$ & II & R1 & $\mathrm{C} 1$ & M1 & A8 & $\mathrm{N} 1$ & $\mathrm{~T} 1$ & E1 & $\mathrm{H} 1$ & {$[20]$} \\
\hline RVA/Pig-tc/USA/OSU/1977/G5P[7] & G5 & $\mathrm{P}[7]$ & 15 & R1 & $\mathrm{C} 1$ & M1 & A1 & N1 & $\mathrm{T} 1$ & E1 & $\mathrm{H} 1$ & {$[20]$} \\
\hline RVA/Pig-wt/GHA/14/2016/G5P[7] & G5 & $P[7]$ & 15 & R1 & C1 & M1 & A8 & N1 & T7 & E1 & H1 & \begin{tabular}{|l|} 
This study \\
\end{tabular} \\
\hline RVA/Human-wt/CHN/LL4260/2000/G5P [6] & G5 & $\mathrm{P}[6]$ & $\mathrm{I} 12$ & R1 & $\mathrm{C} 1$ & M1 & $\mathrm{A} 1$ & N1 & $\mathrm{T} 1$ & E1 & $\mathrm{H} 1$ & [9] \\
\hline RVA/Human-tc/VNM/NT0042/2007/G4P[6] & G4 & $\mathrm{P}[6]$ & I1 & R1 & $\mathrm{C} 1$ & M1 & $\mathrm{A} 8$ & N1 & T1 & E1 & $\mathrm{H} 1$ & {$[15]$} \\
\hline RVA/Human-wt/COD/KisB332/2008/G4P[6] & G4 & $\mathrm{P}[6]$ & I1 & R1 & $\mathrm{C} 1$ & M1 & $\mathrm{A} 1$ & N1 & $\mathrm{T} 7$ & E1 & $\mathrm{H} 1$ & {$[18]$} \\
\hline RVA/Human-wt/BEL/BE2001/2009/G9P[6] & G9 & $\mathrm{P}[6]$ & 15 & R1 & $\mathrm{C} 1$ & M1 & A8 & $\mathrm{N} 1$ & $\mathrm{~T} 7$ & E1 & $\mathrm{H} 1$ & {$[17]$} \\
\hline RVA/Human-wt/CHN/LL3354/2000/G5P[6] & G5 & $\mathrm{P}[6]$ & 15 & R1 & $\mathrm{C} 1$ & M1 & $\mathrm{A} 1$ & $\mathrm{~N} 1$ & $\mathrm{~T} 1$ & E1 & $\mathrm{H} 1$ & Direct submission \\
\hline RVA/Human-wt/TWN/07-96s1118/2007/G9P[19] & G9 & $\mathrm{P}[19]$ & $\mathrm{I} 12$ & R1 & $\mathrm{C} 1$ & M1 & A8 & N1 & $\mathrm{T} 1$ & E1 & $\mathrm{H} 1$ & {$[10]$} \\
\hline RVA/Human-wt/VNM/NT0073/2007/G9P[19] & G9 & $\mathrm{P}[19]$ & I5 & R1 & $\mathrm{C} 1$ & M1 & A8 & N1 & $\mathrm{T} 7$ & E1 & $\mathrm{H} 1$ & [21] \\
\hline RVA/Pig-wt/USA/OK.5.68/2008/G5P[7] & G5 & $\mathrm{P}[7]$ & 15 & R1 & $\mathrm{C} 1$ & M1 & A8 & N1 & T1 & E1 & $\mathrm{H} 1$ & Direct submission \\
\hline RVA/Pig-tc/KOR/174-1/2006/G8P[7] & G8 & $\mathrm{P}[7]$ & $\mathrm{I} 5$ & R1 & $\mathrm{C} 1$ & M2 & $\mathrm{A} 1$ & N1 & $\mathrm{T} 1$ & E1 & $\mathrm{H} 1$ & [22] \\
\hline RVA/Giant panda-tc/CHN/CH-1/2008/G1P[7] & G1 & $\mathrm{P}[7]$ & 15 & R1 & $\mathrm{C} 1$ & M1 & $\mathrm{A} 1$ & N1 & $\mathrm{T} 1$ & E1 & $\mathrm{H} 1$ & {$[14]$} \\
\hline RVA/Pig-wt/TWN/2-3/2015/G9P[13] & G9 & $\mathrm{P}[13]$ & I12 & $\mathrm{R} 1$ & $\mathrm{C} 1$ & M1 & A8 & $\mathrm{N} 1$ & $\mathrm{~T} 1$ & E1 & $\mathrm{H} 1$ & {$[10]$} \\
\hline RVA/Pig-wt/TWN/3-17/2015/G9P[23] & G9 & $\mathrm{P}[23]$ & $\mathrm{I} 12$ & R1 & $\mathrm{C} 1$ & M1 & A8 & $\mathrm{N} 1$ & $\mathrm{~T} 1$ & E1 & $\mathrm{H} 1$ & {$[10]$} \\
\hline RVA/Pig-wt/CHN/NMTL/2008/G9P[23] & G9 & $\mathrm{P}[23]$ & I5 & R1 & $\mathrm{C} 1$ & M1 & A8 & N1 & $\mathrm{T} 1$ & E1 & $\mathrm{H} 1$ & {$[19]$} \\
\hline RVA/Pig-wt/BEL/12R041/2012/G9P[13] & G9 & $\mathrm{P}[13]$ & I5 & R1 & $\mathrm{C} 1$ & M1 & A8 & $\mathrm{N} 1$ & $\mathrm{~T} 7$ & E1 & $\mathrm{H} 1$ & [4] \\
\hline RVA/Pig-wt/THA/CMP45/08/2008/G9P[23] & G9 & $\mathrm{P}[23]$ & 15 & R1 & $\mathrm{C} 1$ & M1 & A8 & N1 & $\mathrm{T} 7$ & E1 & $\mathrm{H} 1$ & {$[23]$} \\
\hline RVA/Pig-wt//TA/2CR/2009/G9P[23] & G9 & $\mathrm{P}[23]$ & I5 & R1 & $\mathrm{C} 1$ & M1 & A8 & N1 & $\mathrm{T} 7$ & E1 & H1 & {$[24]$} \\
\hline RVA/Human-wt/GHA/Ghan-005/2008/G1P[8] & G1 & $\mathrm{P}[8]$ & $\mathrm{I} 2$ & $\mathrm{R} 1$ & $\mathrm{Cl}$ & M1 & $\mathrm{A} 1$ & N1 & $\mathrm{T} 1$ & E1 & $\mathrm{H} 1$ & {$[25]$} \\
\hline RVA/Human-wt/SEN/MRC-DPRU2051/2009/G9P[8] & G9 & $\mathrm{P}[8]$ & I1 & R1 & $\mathrm{C} 1$ & M1 & $\mathrm{A} 1$ & $\mathrm{~N} 1$ & $\mathrm{~T} 1$ & E1 & $\mathrm{H} 1$ & Direct submission \\
\hline RVA/Human-wt/TGO/MRC-DPRU2229/XXXX/G9P[8] & G9 & $\mathrm{P}[8]$ & II & R1 & $\mathrm{C} 1$ & M1 & $\mathrm{A} 1$ & N1 & $\mathrm{T} 1$ & E1 & $\mathrm{H} 1$ & Direct submission \\
\hline
\end{tabular}

The Ghanaian porcine RVA strain 14 (RVA/Pig-wt/GHA/14/2016/G5P[7]) genotype constellation is shown in bold in comparison to reference RVA human strains, Wa and DS-1, and porcine strains, Gottfried and OSU; strains that were fully characterised in GenBank with the top BLASTn hits for each strain 14 segment; three typical porcine strains of the GX-P[X]-15-R1-C1-M1-A8-N1-T7-E1-H1 constellation; and three human strains from West Africa. Green - Wa-like genogroup; pink -DS-

1-like genogroup; blue - typical porcine genotype [4]

(iii.)Viral replication enzymes (VP1 and VP3) and core scaffold protein (VP2): Strain 14 genomic segments 1, 2 and 3 all clustered within genotype 1 (Wa-like) of the corresponding genes (Figs. 4, 5, 6). For VP1, the most homologous sequences came from a human and a pig in Taiwan, isolated in 2007 and 2015 respectively (Table 1 ). These Taiwanese strains were sequenced as part of the same study, which concluded that the similarity of the human strain to those detected in pigs was suggestive of zoonotic origin [10]. This conclusion is supported by our phylogenetic analysis, which shows a separate R1 clade containing the human Wa-like isolates (Fig. 4). Similar to VP1, phylogenetic analysis of VP2 produced 2 major sub-clusters within the $\mathrm{C} 1$ clade: one containing only human strains and one predominantly containing pig strains (Fig. 5). The VP2 segment of strain 14 formed part of a small outgroup within the latter clade, suggesting that this segment originates from a pig lineage. The outgroup contained two closely related Chinese strains from 2017 (94\% nucleotide identity), and a more distantly related human-derived strain from a paediatric patient in Hungary (88\% nucleotide identity), thought to be a further case of pig-human transmission, due to its similarity to known pig strains [11]. The VP3 segment M1 clade again showed 2 major sub-clusters separating strains of pig and human origin (Fig. 6). However, the strain 14 VP3 segment formed part of a smaller clade. This clade predominantly contained porcine strains, suggesting a porcine ancestral origin, but the strain
14 segment itself was most similar to a 2008 strain from a giant panda and two human strains (2000 and 2010), all from China (Table 1) [9, 14]. Nucleotide similarities of $94-95 \%$ to strain 14 suggest that cross-species transmission is likely to have occurred.

(iv.)Non-structural proteins (NSP1-5/6): The interferon antagonist non-structural protein 1 , NSP1, of strain 14 was most closely related to a group of human and porcine strains from Vietnam (Table 1) $[15,16]$. On phylogenetic analysis, the segment clustered with the A8 clade. This clade constituted porcine isolates with only occasional human isolates (Fig. 7). The ancestral origin of this strain 14 segment is therefore suggested to be porcine as these are the dominant isolates in its cluster. The NSP2 (viroplasm-associated protein) segment 8 of strain 14 was most similar to a 2015 porcine isolate and a 2007 human isolate both from Taiwan (Table 1) [10]. These cluster in the N1 clade which had 3 major sub-clusters (Fig. 8). The first contained only porcine isolates. The second and third sub-clusters came from a common branch and within each there are further sub-groups that show either pig or human specificity. Segment 8 of strain 14 clustered in a minor sub-group that contained both porcine and human isolates which is within a porcine isolate dominated sub-cluster suggesting the ancestral origin of this segment was from pig. Segment 7 NSP3 (translation enhancer protein) of strain 14 was most homologous at the nucleotide level to two strains of human origin, a 2009 isolate 


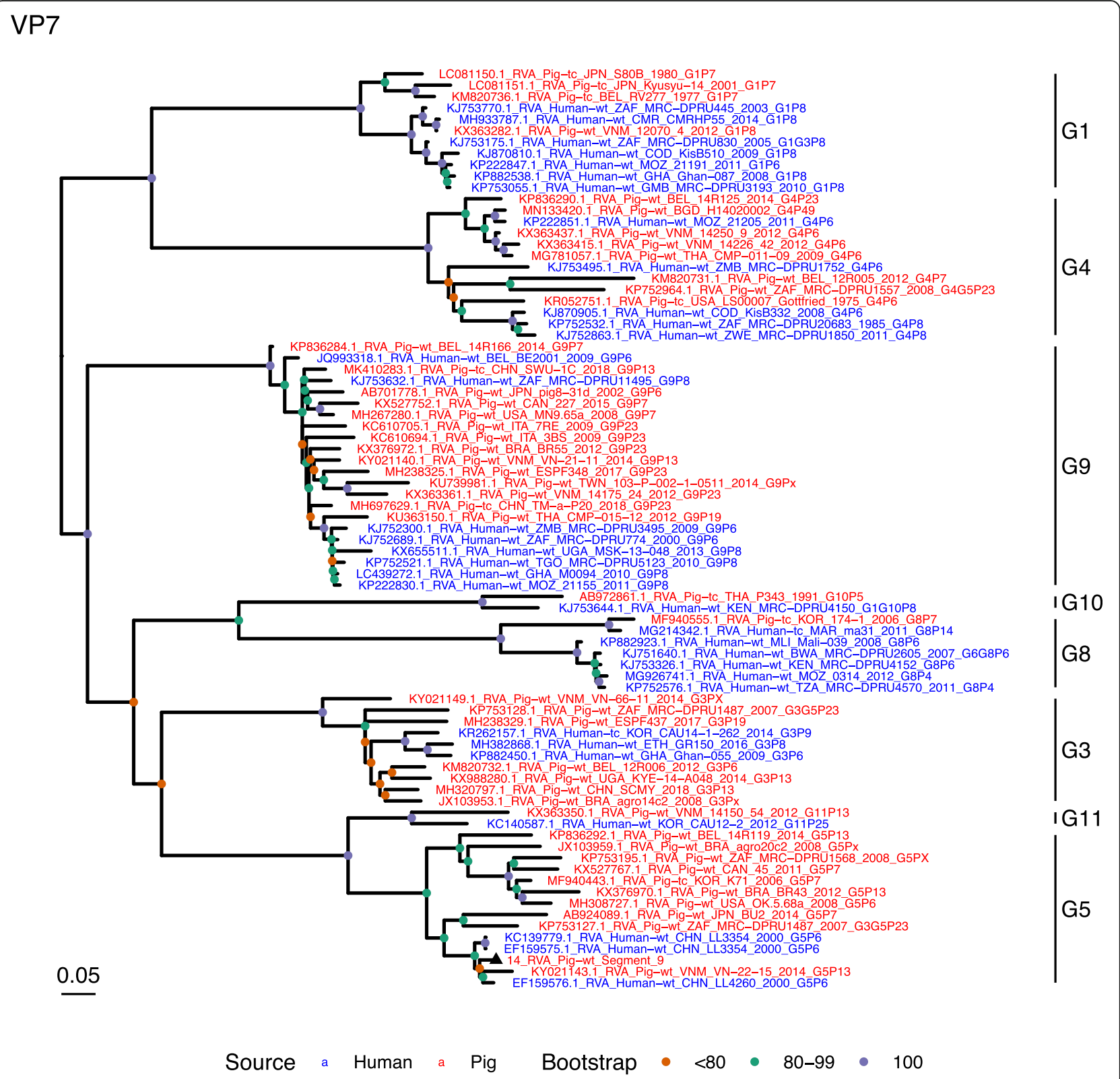

Fig. 1 Maximum Likelihood Phylogeny of VP7, genomic segment 9. The tree includes global pig RVA strains and African strains of human origin retrieved from GenBank. We also included the three most closely related RVA strain segments, as identified by BLASTn, regardless of origin. Clades containing large clusters of closely related or identical sequences were pruned to show representative viral strains

from Belgium and a 2008 isolate from Côte d'Ivoire (Table 1) $[17,18]$. These form a distinct cluster within the T7 genotype clade, which is largely porcine-dominated (Fig. 9). It is hard to definitely suggest a likely origin of the strain 14 segment 7 due to the even mix of porcine and human strains. However, outside of this cluster, the T7 genotype contains only pig strains, and so a porcine origin is most-likely. The viral enterotoxin (NSP4) genomic segment 10 was most homologous at the nucleotide level with two pig isolates from China, one from
2008 and one from 2015 (Table 1). These cluster in the E1 clade (Fig. 10). The E1 clade is broadly separated into sub-clusters of either human or porcine origin with only 2 small sub-groups showing mixed origin. Strain 14's segment 10 was in a pig dominated sub-group although there was a closely related 2000 human isolate LL3354 from China also within this group. This would suggest that this genomic segment is of porcine origin. The viroplasmassociated non-structural protein, NSP5, from segment 11 was most similar to two 2008 pig isolates; 
VP4

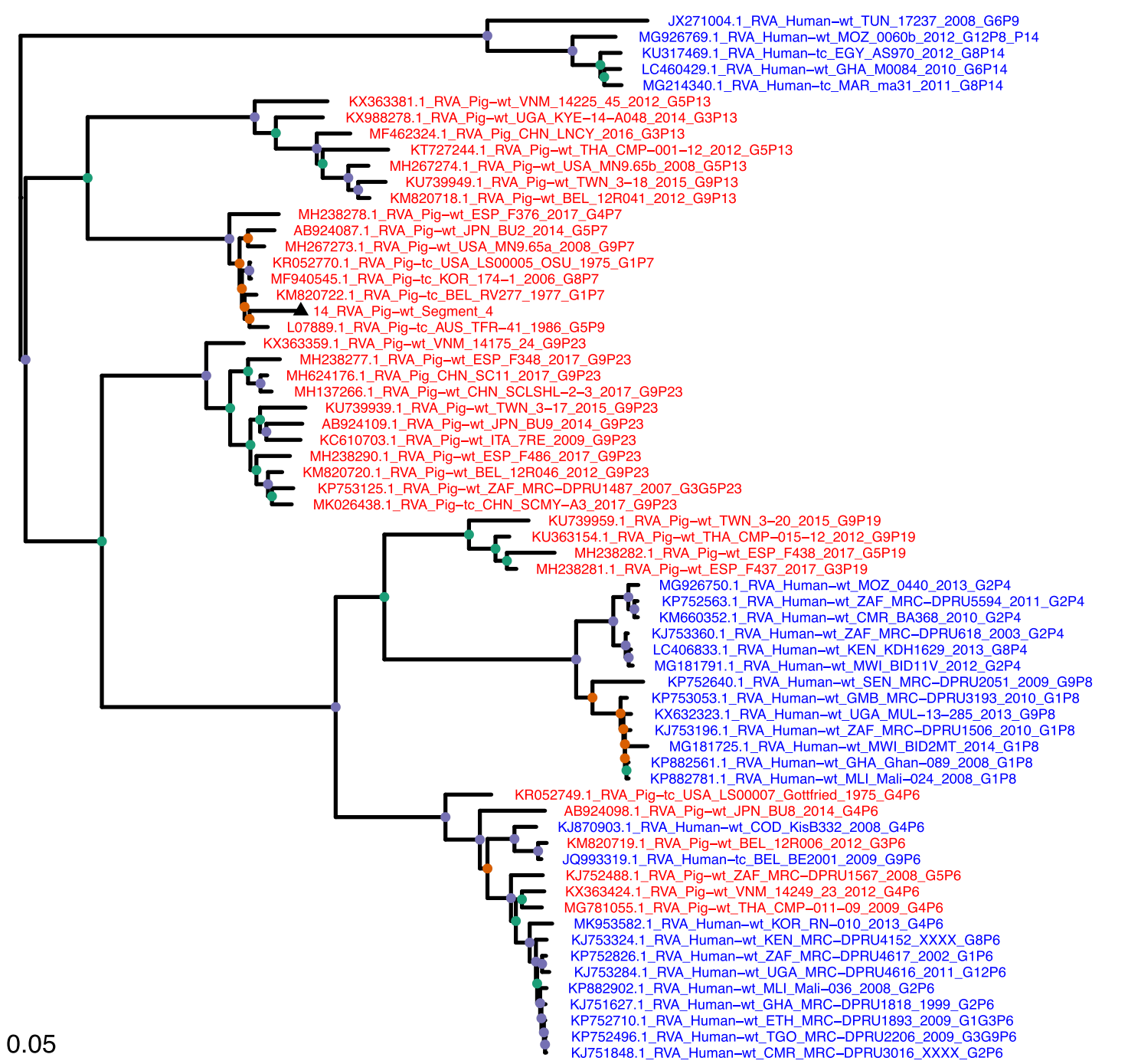
KJ75104__ARA_Human_W_TGO_MRC_DPRU220_200_G3G9P6

Source a Human a Pig Bootstrap • $<80$ • 80-99 100

Fig. 2 Maximum Likelihood Phylogeny of VP4, genomic segment 4. The tree includes global pig RVA strains and African strains of human origin retrieved from GenBank. We also included the three most closely related RVA strain segments, as identified by BLASTn, regardless of origin. Clades containing large clusters of closely related or identical sequences were pruned to show representative viral strains

one from USA and one from China (Table 1) [19]. The maximum-likelihood phylogenetic tree of segment 11 showed NSP5 to sit in the H1 clade which had two major sub-clusters; one was human and the other was mixed human and porcine isolates (Fig. 11). The second sub-cluster further differentiated into a human only, a porcine only and a mixed sub-group. Strain 14 was within the mixed subgroup. The majority of strains within this group were porcine, suggesting that this genomic segment was also of a porcine lineage.

\section{Discussion}

We report here the near complete genome of an RVA isolate detected in the faeces of an asymptomatic pig in Ghana. We propose to call this strain RVA/pig-wt/ GHA/14/2016/G5P[7]. The genomic constellation was G5-P[7]-I5-R1-C1-M1-A8-N1-T7-E1-H1, which is similar to prototype porcine RVA strains, in particular to Ugandan isolates sequenced by Amimo et al. (2015) [26] which were G5P[13] and G2, G9 and G11 Canadian strains sequenced by Martel-Paradis et al. (2013) [27] and the porcine lineage genotype constellation described 
VP6

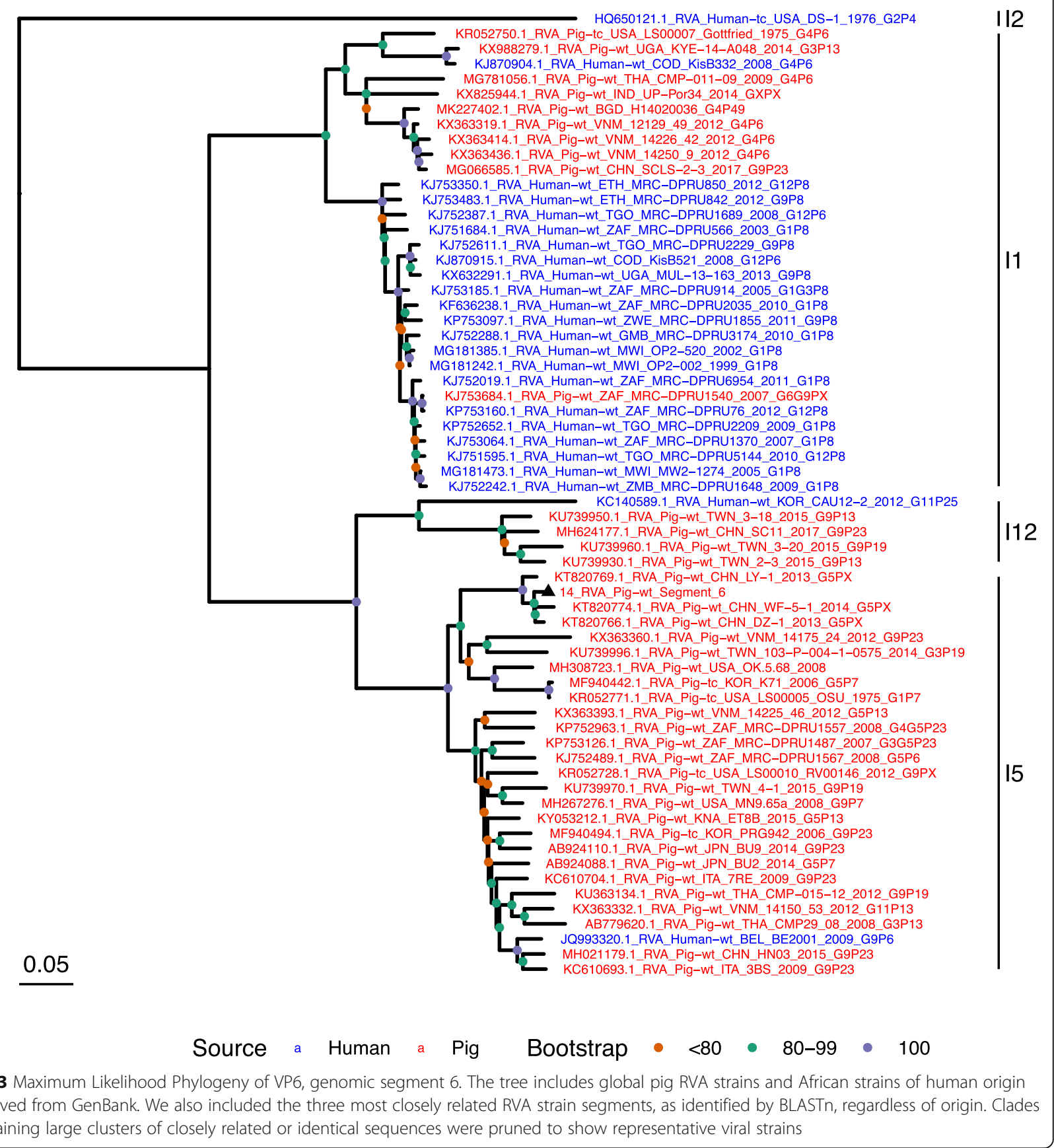

by Theuns et al. (2015) [4] (GX-P[X]-I5-R1-C1-M1-A8N1-T7-E1-H1).

Despite being of a porcine lineage, several segments of strain 14 were found to be most closely related to strains derived from humans. However, phylogenetic analysis suggests that these human strains are more likely to be porcine-like, rather than strain 14 being human-like. Regardless, this similarity between a porcine RVA strain and several human strains provides further evidence that transmission of such porcine RVA strains to humans can occur, and a paucity of RVA sequence data from West Africa makes it difficult to determine whether or not zoonotic cross-species transmission is common in the region. This is important as zoonotic infection of humans by RVA from animals or the re-assortment of virus segments between human and animal rotaviruses to cause antigenic shift and/or increase virulence are considered factors that may affect the effectiveness of 
VP1

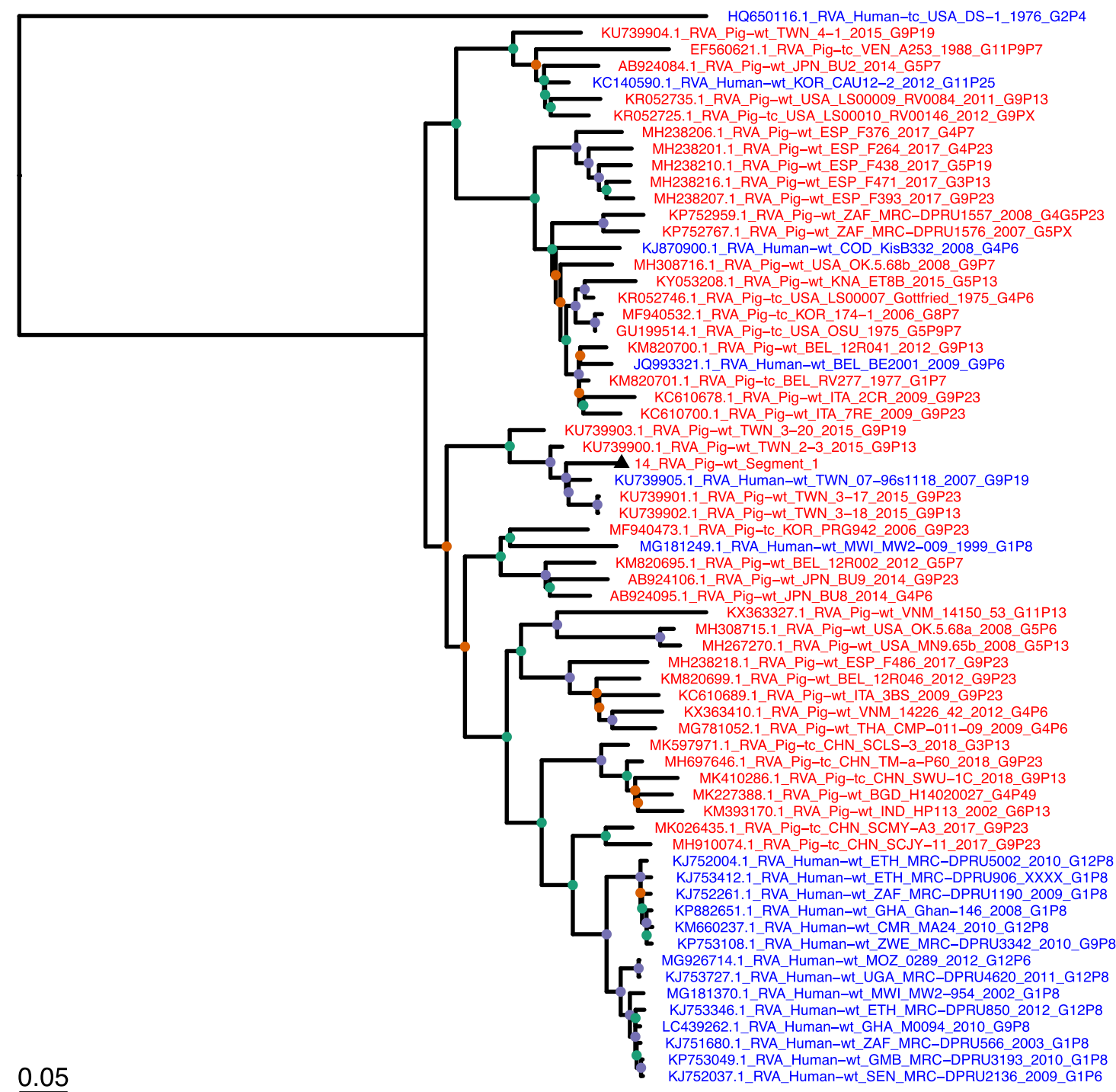

\section{Source a Human a Pig Bootstrap $\bullet<80 \cdot 80-99 \cdot 100$}

Fig. 4 Maximum Likelihood Phylogeny of VP1, genomic segment 1. The tree includes global pig RVA strains and African strains of human origin retrieved from GenBank. We also included the three most closely related RVA strain segments, as identified by BLASTn, regardless of origin. Clades containing large clusters of closely related or identical sequences were pruned to show representative viral strains

rotavirus vaccine campaigns, especially in developing countries where there is documented evidence of mixed infections [28].

Ghana introduced the vaccine Rotarix, a Wa-like vaccine (G1-P[8]-I1-R1-C1-M1-A1-N1-T1-E1-H1), in May 2012. The predominant circulating RVA strains in hospitalized paediatric cases has varied since its introduction [29]. However, Lartey et al. (2018) [29] only characterized the VP4 and VP7 encoding genomic segments in their study. It is therefore difficult to compare the full genome we report here to post-vaccine human samples; although the VP4 and VP7 genotypes of strain 14 are different to those of the local human strains described by Lartey et al. (2018) [29].

It is interesting to note that the pigs and cattle on the farms tested showed no evidence of clinical gastroenteric disease when the samples were taken. Furthermore, the metagenomic sequencing, in addition to sequence reads of RVA, also revealed the presence of other eukaryotic RNA viruses associated with both sub-clinical and clinical gastroenteric infection. This demonstrates that healthy pigs are viral carriers and therefore potential 
VP2

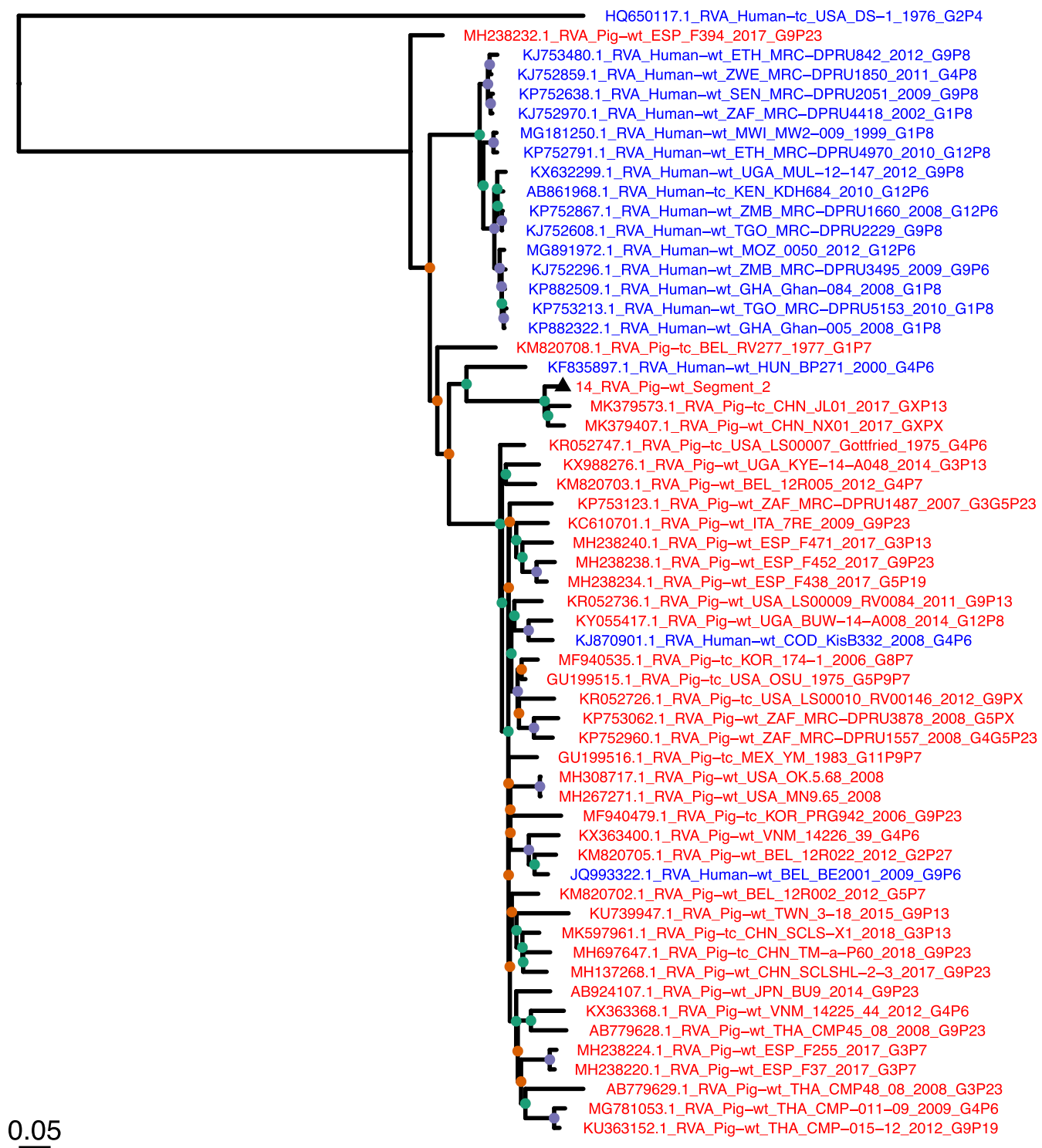

\section{Source a Human a Pig Bootstrap $\bullet<80 \bullet 80-99 \cdot 100$}

Fig. 5 Maximum Likelihood Phylogeny of VP2, genomic segment 2. The tree includes global pig RVA strains and African strains of human origin retrieved from GenBank. We also included the three most closely related RVA strain segments, as identified by BLASTn, regardless of origin. Clades containing large clusters of closely related or identical sequences were pruned to show representative viral strains

sources of infection for other animals. Indeed, in a study analyzing young pig faeces for sub-clinical infection with RVA in East Africa, 26\% of animals were positive for RVA, with a range of $79 \%$ in nursing piglets reducing to $6 \%$ in grower piglets [26]; we were within this range with $10.4 \%$ of the animals sampled (all under 1 year old) in Ghana being positive. Amimo et al. (2015) [26] also showed that infection prevalence varied with pig density, management system and age.
There is a porcine rotavirus vaccine available (Prosystem Rota from Merck Animal Health) which is based on modified porcine RVA strains Gottfried (G4P[6]) and OSU (G5P[7]). This is not known to be used in Ghana. The sequence obtained above is $87 \%$ identical to OSU G5 VP7 whilst it is $96 \%$ identical to human strains (Table 1). This suggests that the strain sequenced here is not vaccine derived and that this is not the reason for its apparent lack of virulence in the sampled pig. 
VP3

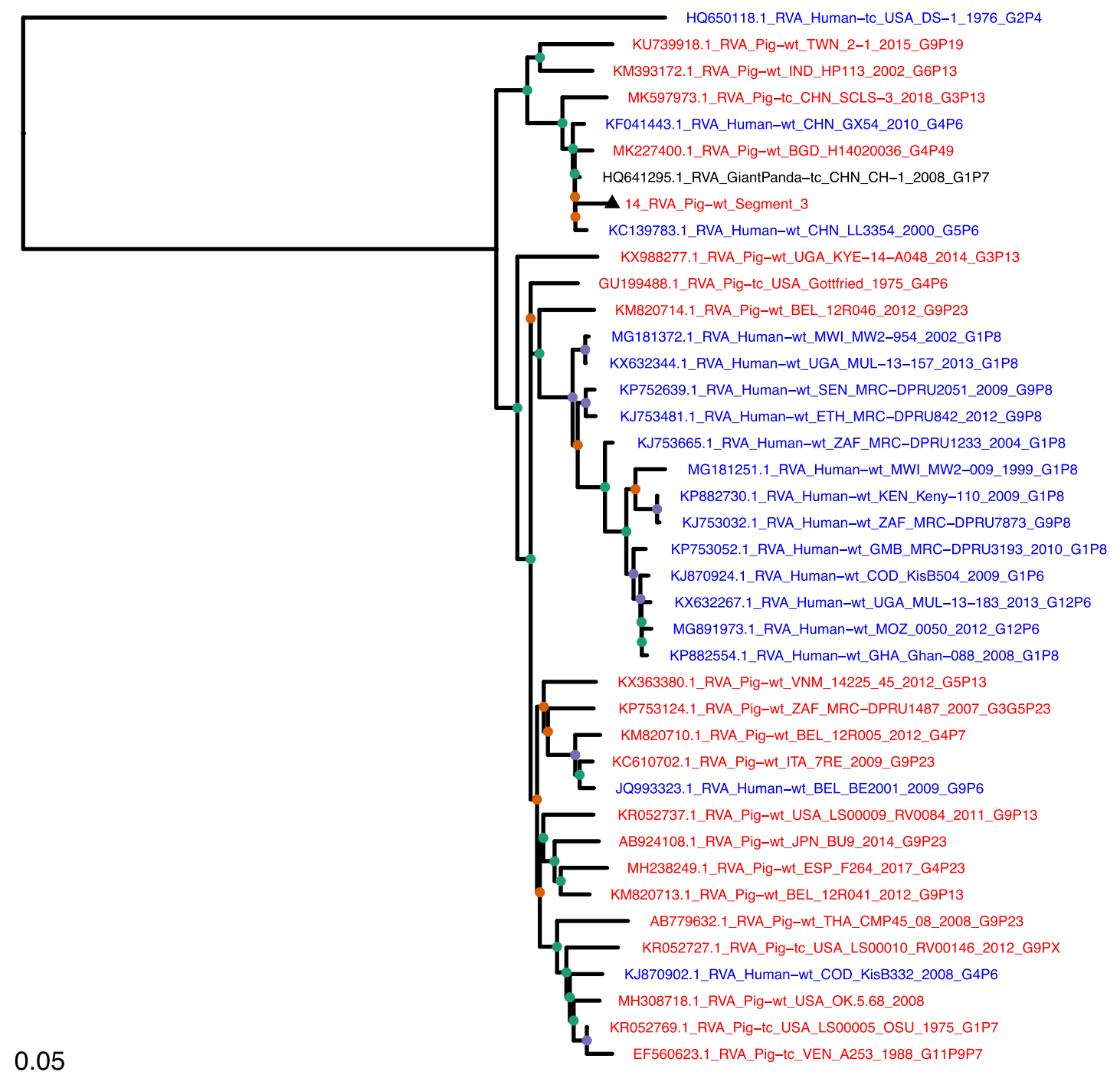

Fig. 6 Maximum Likelihood Phylogeny of VP3, genomic segment 3. The tree includes global pig RVA strains and African strains of human origin retrieved from GenBank. We also included the three most closely related RVA strain segments, as identified by BLASTn, regardless of origin. Clades containing large clusters of closely related or identical sequences were pruned to show representative viral strains

The variation and unusual strains detected by Lartey et al. (2018) [29] in humans suggest selection pressure is occurring by vaccination. This may provide niches for infection by zoonotic RVA strains. The genomic constellation detected in the sub-clinically infected pig in this study contained segment genotypes that have been detected in human infections previously [17, 30, 31]. Sub-clinically infected farm animals are therefore a potential source of virus for infection of humans, with or without reassortment of the different genomic segments.
Finally, it is interesting to note that the isolates with the greatest similarity to strain 14 were predominantly of Asian origin. Whilst it is possible that Asian and West African strains are highly related, it is more likely that this outcome is due to a limited number of porcine RVA sequences from West Africa, demonstrating the importance of this first sequence from an agriculturally important species in Ghana.

\section{Conclusions}

Pigs and cattle carry RVA infection sub-clinically at low frequency. It is possible to sequence the virus in these 


\section{NSP1}

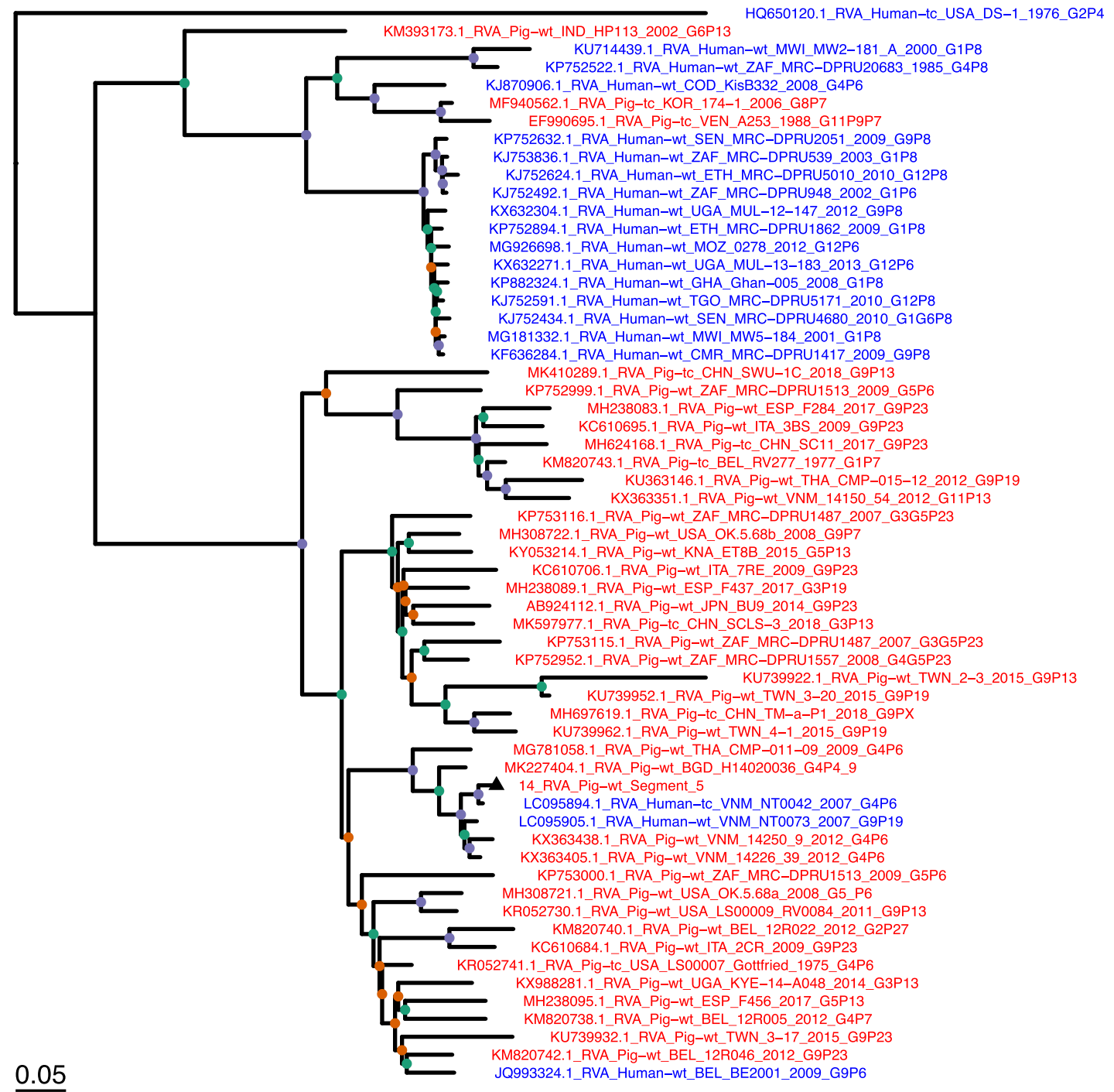

Source a Human a Pig Bootstrap $\bullet \quad<80 \quad 80-99 \quad \bullet \quad 100$

Fig. 7 Maximum Likelihood Phylogeny of NSP1, genomic segment 5. The tree includes global pig RVA strains and African strains of human origin retrieved from GenBank. We also included the three most closely related RVA strain segments, as identified by BLASTn, regardless of origin. Clades containing large clusters of closely related or identical sequences were pruned to show representative viral strains

samples and determine full genome constellation data using a metagenomic approach. The RVA genotype discovered has a porcine-like genome constellation. However, a number of the segments most closely resembled those isolated from humans in suspected cases of zoonotic transmission. Therefore, such viruses may be a source of variable gene segments for re-assortment with other viruses to cause vaccine breakdown. It is recommended that further human and pig strains are characterized in West Africa, to better understand this dynamic.

\section{Methods}

\section{Aim and design of the study}

The study aimed to determine the prevalence and strains of subclinical carriage of rotavirus A in farm animals in Ghana as these are a possible source of infection of humans. Swine and cattle farms located in the northeastern part of Accra were randomly selected for collection of stool samples from clinically normal animals. The samples were collected from animals under 1 year old under aseptic conditions and either stored at $-20^{\circ} \mathrm{C}$ or used to prepare $10 \%$ fecal suspensions in phosphate-buffered saline 


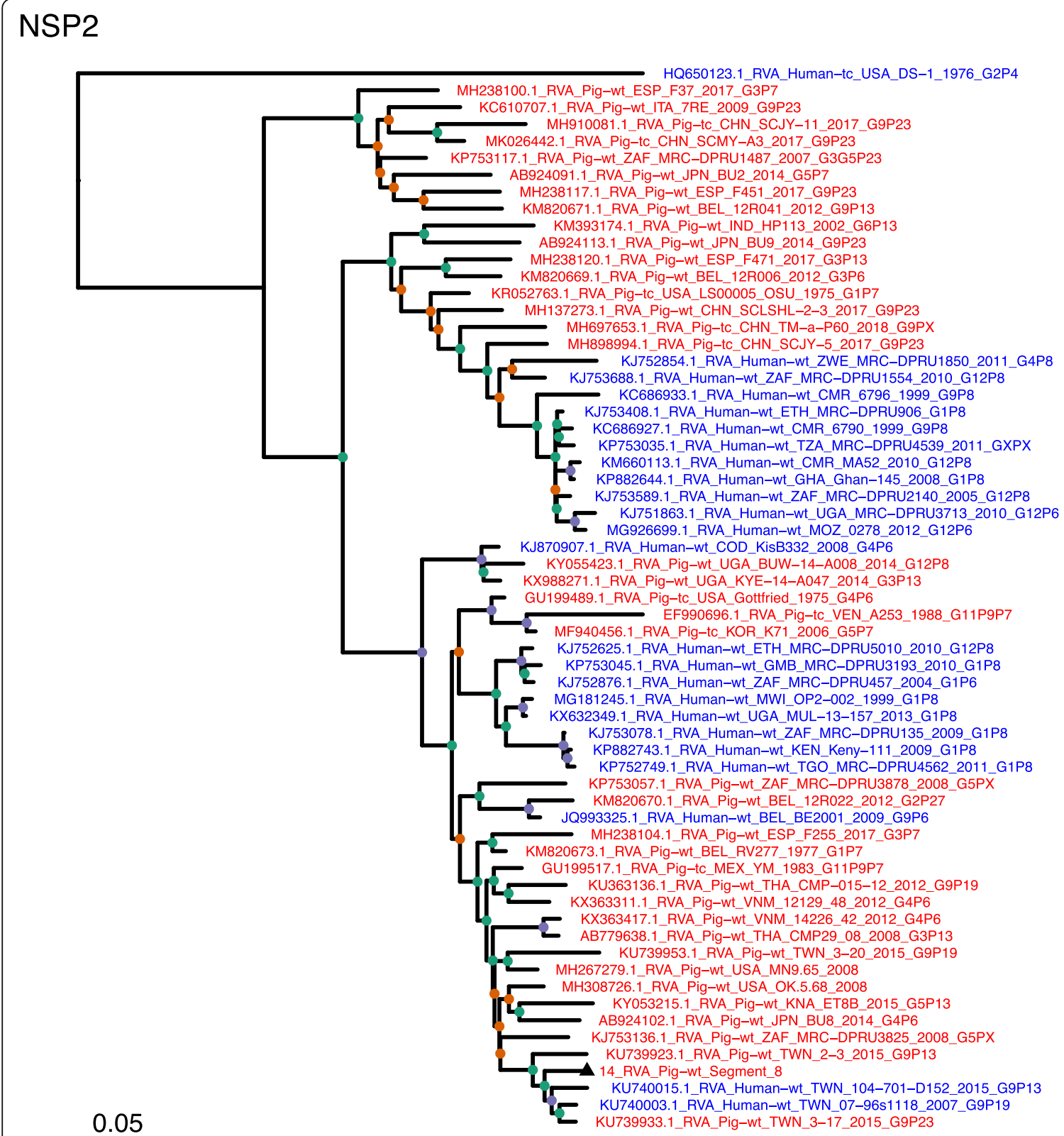

Source a Human a Pig Bootstrap $\bullet<80 \quad 80-99 \cdot 100$

Fig. 8 Maximum Likelihood Phylogeny of NSP2, genomic segment 8. The tree includes global pig RVA strains and African strains of human origin retrieved from GenBank. We also included the three most closely related RVA strain segments, as identified by BLASTn, regardless of origin. Clades containing large clusters of closely related or identical sequences were pruned to show representative viral strains

solution. The suspensions were vortexed, centrifuged at $600 \mathrm{x} \boldsymbol{g}$ for $10 \mathrm{~min}$, and the supernatant used in an immunochromatographic assay for the detection of rotavirus antigen and for total RNA extraction. The immunochromatographic assay was performed using the ProFlow Rotavirus test kit following the manufacturer's manual.

Total RNA was extracted from the samples that were positive for rotavirus antigen using the GenElute extraction kit (Sigma Aldrich) with some modifications. Briefly, $350 \mu \mathrm{L}$ of $10 \%$ stool suspension supernatant were mixed with an equal volume of GenElute lysis buffer, $350 \mu \mathrm{L} 70 \%$ ethanol added and vortexed. The mixture was spun through a GenElute filtration column. $750 \mu \mathrm{L}$ of Trizol was added to the filtrate, vortexed, and incubated at room temperature for 5 min. Chloroform $(200 \mu \mathrm{L})$ was added to the mixture, 
NSP3

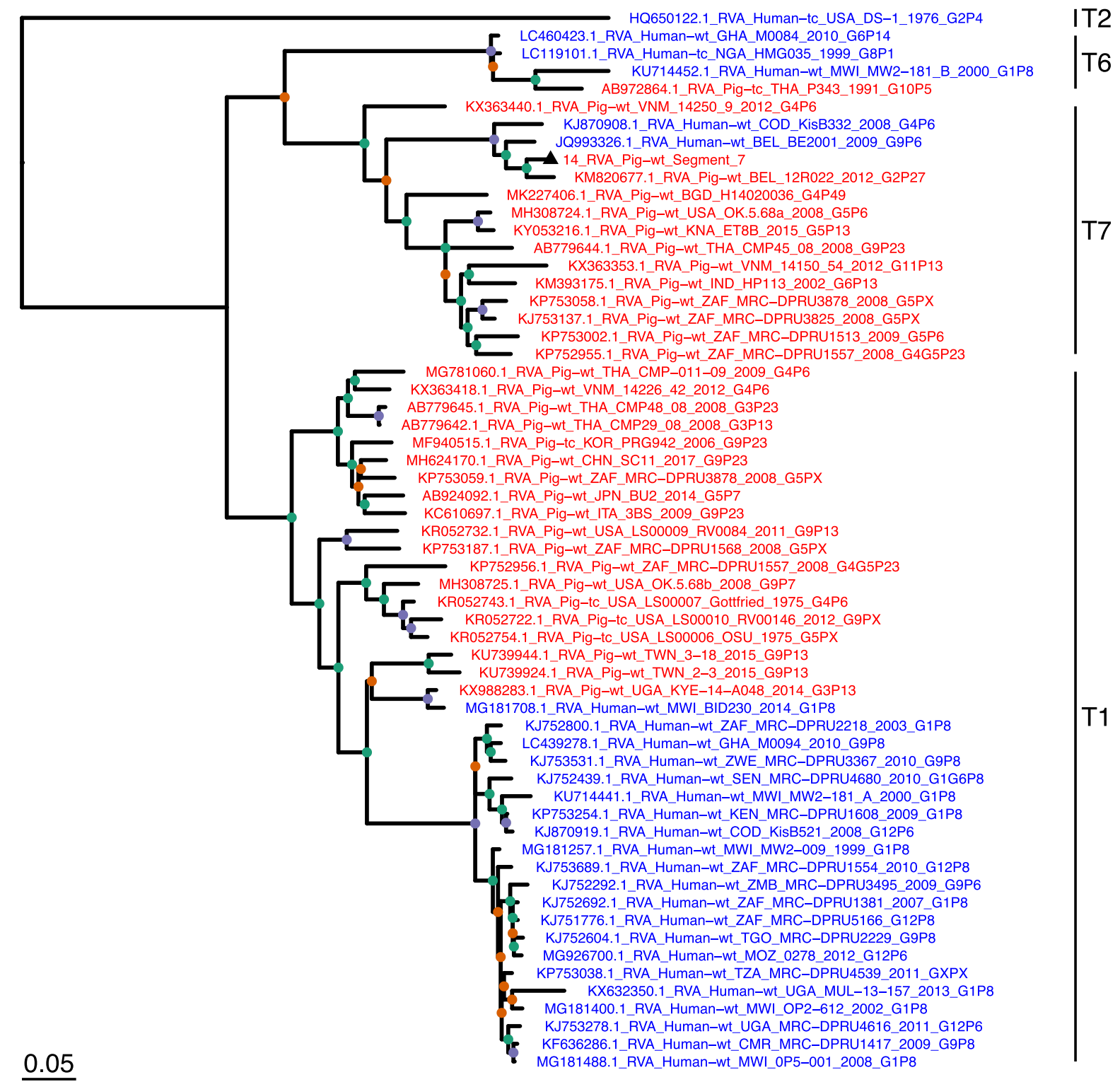

Source a Human a Pig Bootstrap • $<80 \quad \bullet \quad 80-99 \quad \bullet \quad 100$

Fig. 9 Maximum Likelihood Phylogeny of NSP3, genomic segment 7. The tree includes global pig RVA strains and African strains of human origin retrieved from GenBank. We also included the three most closely related RVA strain segments, as identified by BLASTn, regardless of origin. Clades containing large clusters of closely related or identical sequences were pruned to show representative viral strains

vortexed, and incubated at room temperature for 3 min. The mixture was centrifuged at $300 \times g$ for 5 min and $250 \mathrm{uL}$ of the clear upper phase was pipetted off and mixed with $250 \mu \mathrm{L}$ of $70 \%$ ethanol. The mixture was transferred to a GenElute binding column and the normal RNA purification method then followed. Two lots of $30 \mu \mathrm{L}$ elution solution were used, collecting both eluates in the same tube for a higher RNA yield. The concentration and purity of the extracted RNA was determined by the NanoDrop spectrophotometer.

\section{Reverse transcriptase-PCR}

Sample RNA was first tested for the presence of rotavirus using a one-step NSP3 RT-PCR [32]. This was performed using the Kapa Probe Fast Universal One-Step 
NSP4

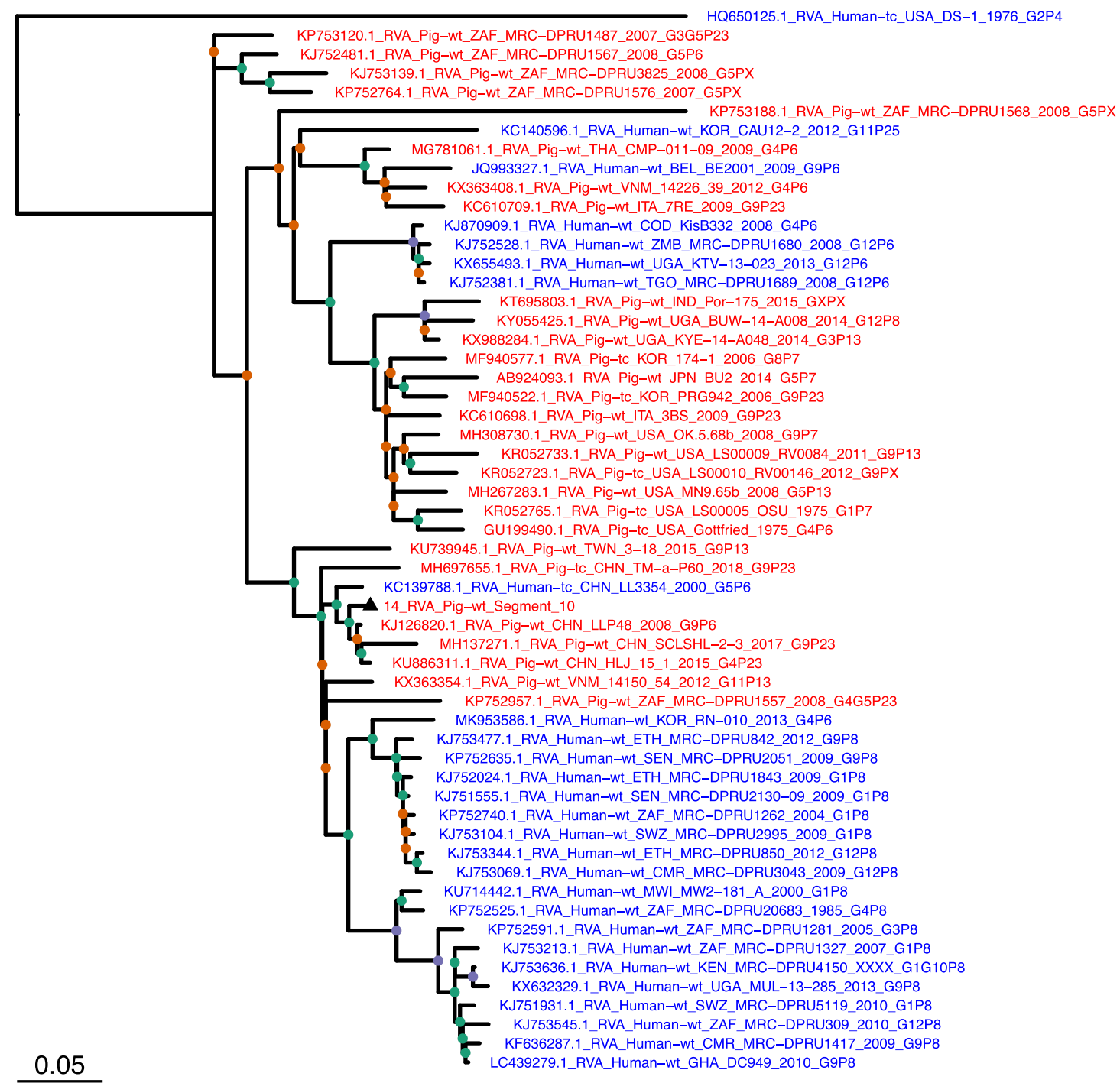

\section{Source a Human a Pig Bootstrap • $<80 \quad 80-99 \quad \bullet \quad 100$}

Fig. 10 Maximum Likelihood Phylogeny of NSP4, genomic segment 10. The tree includes global pig RVA strains and African strains of human origin retrieved from GenBank. We also included the three most closely related RVA strain segments, as identified by BLASTn, regardless of origin. Clades containing large clusters of closely related or identical sequences were pruned to show representative viral strains

qRT-PCR kit and the manufacturer's conditions with RNA diluted $1 / 5$ and the primers (NSP3-F, NSP3-R) and probe (NSP3-p) from Zeng et al. (2008) [32] (Table 3). The reaction conditions were $42^{\circ} \mathrm{C}$ for $5 \mathrm{~min}, 95^{\circ} \mathrm{C}$ for $5 \mathrm{~min}$, then 40 cycles of $95^{\circ} \mathrm{C}$ for $5 \mathrm{~s}, 60^{\circ} \mathrm{C}$ for $30 \mathrm{~s}$ and these were performed in a Rotorgene 600 (Qiagen). The RNA was then tested for the presence of genomic segment 6 (VP6) using the rotavirus group A specific primers VP6F and VP6R from Iturriza-Gomara et al. (2002) [33] (Table 3). Reverse transcription was first carried out using Superscript III (ThermoFisher Scientific) and random hexamer primers as per the manufacturer's instructions, RNAse $\mathrm{H}$ treated, then cDNA was diluted $1 / 5$ and taken into a PCR with Platinum Pfx $\left(94{ }^{\circ} \mathrm{C}\right.$ for $5 \mathrm{~min}, 35$ cycles of $94^{\circ} \mathrm{C}$ for $15 \mathrm{~s}, 55^{\circ} \mathrm{C}$ for 30 $\mathrm{s}, 68^{\circ} \mathrm{C}$ for $30 \mathrm{~s}$ with a final extension of $68^{\circ} \mathrm{C}$ for 10 $\mathrm{min})$. This reaction gave a predicted band size of $380 \mathrm{bp}$ which was detected on a $2 \%$ agarose gel. If present, the band was purified from the gel and sequenced using the Sanger sequencing method and VP6F as primer. 
NSP5

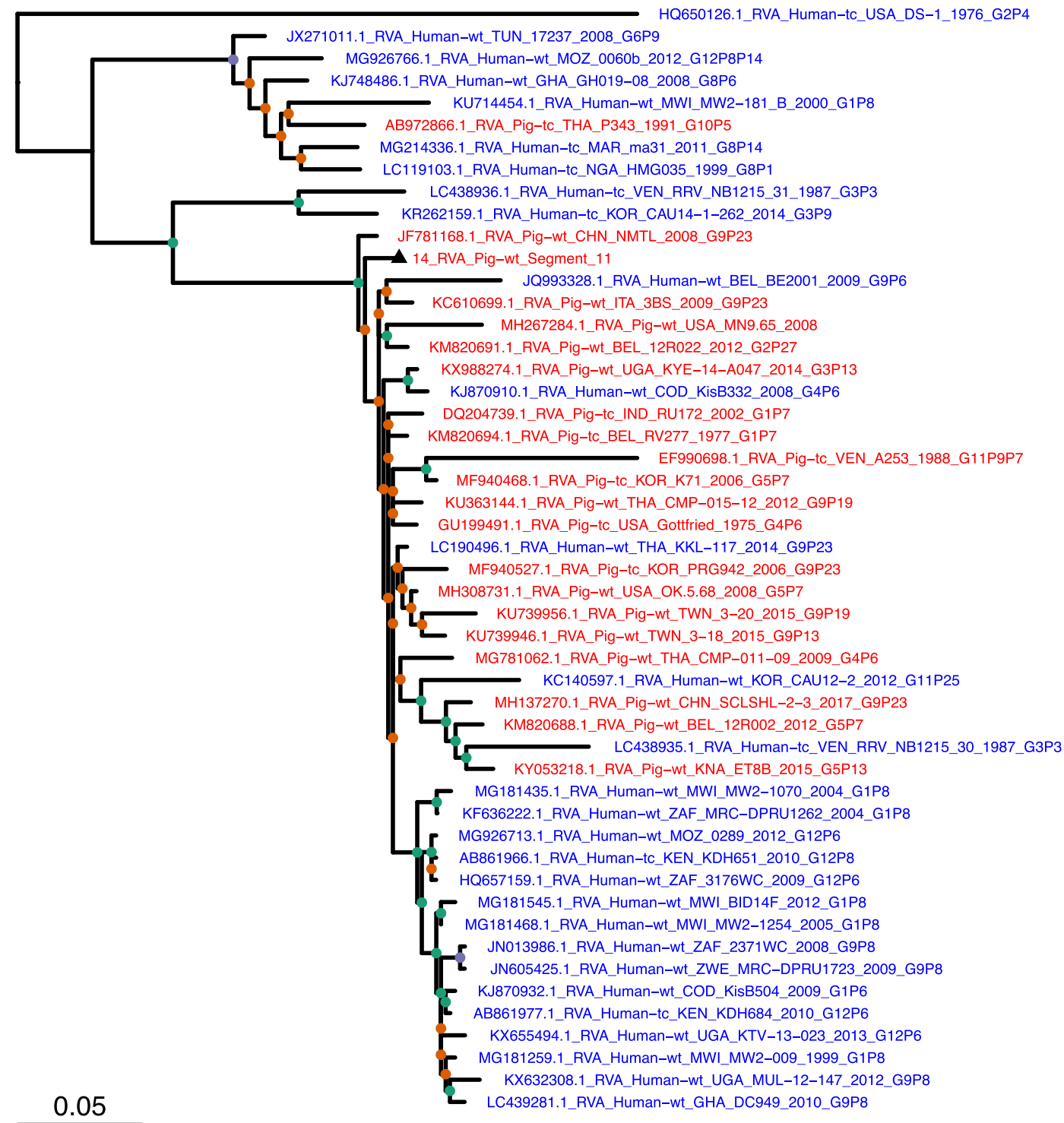

Source a Human a Pig Bootstrap • $<80 \quad 80-99 \cdot 100$

Fig. 11 Maximum Likelihood Phylogeny of NSP5, genomic segment 11. The tree includes global pig RVA strains and African strains of human origin retrieved from GenBank. We also included the three most closely related RVA strain segments, as identified by BLASTn, regardless of origin. Clades containing large clusters of closely related or identical sequences were pruned to show representative viral strains

\section{Metagenomic sequencing Illumina library preparation and sequencing}

RNA was reverse transcribed and amplified following a sequence-independent single-primer amplification and reverse transcription (SISPA-RT) protocol as previously described [34]. Briefly, $5 \mu \mathrm{L}$ of RNA was combined with $1 \mu \mathrm{l}$ of $10 \mu \mathrm{M}$ primer FR26RV-N (Table 3), $1 \mu \mathrm{L}$ of 10 $\mathrm{mM}$ dNTPs, and $6 \mu \mathrm{l}$ of RNase-free water. The mixture was heated to $65^{\circ} \mathrm{C}$ for $5 \mathrm{~min}$ and placed on ice before adding a mastermix consisting of: $1 \mu \mathrm{l}(40 \mathrm{U})$ of RNase OUT (Thermo Fisher Scientific); $1 \mu \mathrm{l}$ (200 U) of Superscript III reverse-transcriptase (Thermo Fisher Scientific); $4 \mu \mathrm{l}$ of $5 \mathrm{X}$ Superscript III reaction buffer; and $1 \mu \mathrm{L}$ of $0.1 \mathrm{M}$ dithiothreitol, to give a final volume of $20 \mu \mathrm{L}$. The mixture was incubated in a thermocycler at $25^{\circ} \mathrm{C}$ for $5 \mathrm{~min}$, followed by $50 \mathrm{~min}$ at $50^{\circ} \mathrm{C}$. The reaction was terminated by heating to $94{ }^{\circ} \mathrm{C}$ for $3 \mathrm{~min}$, and then cooled to $4{ }^{\circ} \mathrm{C}$. Second-strand cDNA synthesis was 
Table 3 Primers and probes used in RT-PCR

\begin{tabular}{|c|c|c|c|c|}
\hline Genome Segment & Protein & Primer/probe sequence & Predicted product size (bp) & Reference \\
\hline 7 & NSP3 & $\begin{array}{l}\text { NSP3-F: ACCATCTWCACRTRACCCTCTATGAG } \\
\text { NSP3-R: GGTCACATAACGCCCCTATAGC } \\
\text { NSP3-p: FAM5'-AGTTAAAAGCTAACACTGTCAAA-3'MGB }\end{array}$ & $87 \mathrm{bp}$ & {$[32]$} \\
\hline 6 & VP6 & $\begin{array}{l}\text { VP6F: GACGGVGCRACTACATGGT } \\
\text { VP6R: GTCCAATTCATNCCTGGTGG }\end{array}$ & $380 \mathrm{bp}$ & [33] \\
\hline 2 & VP2 & $\begin{array}{l}\text { VP2F1: ACAAGCGGCAAATGACTGTT } \\
\text { VP2R1: GGTTGATGACTTGTCCACTCC }\end{array}$ & $398 \mathrm{bp}$ & This paper \\
\hline \multirow[t]{2}{*}{11} & NSP5 & $\begin{array}{l}\text { NSP5F1: ACAACGTCAACTCTTTCTGGA } \\
\text { NSP5R1: TGCTTGAAGGTCGTGATTGC }\end{array}$ & $232 \mathrm{bp}$ & This paper \\
\hline & SISPA & $\begin{array}{l}\text { FR26RV-N: GCCGGAGCTCTGCAGATATCNNNNNN } \\
\text { FR20RV: GCCGGAGCTCTGCAGATATC }\end{array}$ & & {$[34]$} \\
\hline
\end{tabular}

performed by adding $0.5 \mu \mathrm{l}(2.5 \mathrm{U})$ of large Klenow fragment (New England Biolabs) to each reaction and incubating at $37^{\circ} \mathrm{C}$ for $60 \mathrm{~min}$ followed by $75^{\circ} \mathrm{C}$ for $10 \mathrm{~min}$ to inactivate the enzyme.

SISPA amplification was performed in duplicate for each sample, using the cDNA reaction mixture as direct input. The final reaction mixture consisted of $5 \mu \mathrm{l}$ of cDNA, $2 \mu \mathrm{l}$ of $10 \mu \mathrm{M}$ primer FR20RV (Table 3), $1 \mu \mathrm{l}$ of $10 \mathrm{mM}$ dNTP mixture, $0.5 \mu \mathrm{l}$ of Phusion DNA polymerase (Thermo Fisher Scientific), $10 \mu \mathrm{l}$ of $5 \mathrm{X}$ Phusion high-fidelity reaction buffer and $31.5 \mu$ l of nuclease-free water. The PCR reaction was performed by heating to $98^{\circ} \mathrm{C}$ for $30 \mathrm{~s}$ followed by 14 cycles of $98^{\circ} \mathrm{C}$ for $10 \mathrm{~s}$, $62{ }^{\circ} \mathrm{C}$ for $30 \mathrm{~s}, 72{ }^{\circ} \mathrm{C}$ for $120 \mathrm{~s}$ followed by a final extension at $72{ }^{\circ} \mathrm{C}$ for $10 \mathrm{~min}$. Duplicate reactions were combined and the amplified DNA was purified using KAPA PureBeads (Roche) at a 1:1 ratio, eluting in $20 \mu \mathrm{l}$ of buffer EB (Qiagen).

DNA was fragmented to an average length of $400 \mathrm{bp}$ by sonication (microTUBEs, Covaris) and indexed Illumina sequencing libraries were prepared from the fragmented DNA using the NEBNext Ultra II DNA library preparation kit (NEB). $2 \times 150 \mathrm{bp}$ paired-end reads were generated on the Illumina MiSeq using v3 reagent chemistry, producing approximately $2.5 \times 10^{6}$ reads per sample.

\section{Sequence data analysis}

Sequencing data was de-multiplexed and imported to the CLC Genomics Workbench software (Qiagen) for analysis. The reads were trimmed to remove lowcomplexity and low-quality regions together with the SISPA primer sequence. The trimmed reads were then mapped to a custom database containing the reference genomes of 1377 vertebrate viruses taken from the NCBI RefSeq database [35]. To account for strain variability, the mapping parameters allowed for up to $36 \%$ mismatch between reads and the reference sequence $(80 \%$ identity over $80 \%$ of the read). Majority consensus sequences generated by mapping were extracted and confirmed by alignment to the complete nucleotide database using the NCBI BLASTn tool [36]. The sequence with the best match was downloaded and used as a reference for a second round of mapping in order to generate the most complete alignment possible. Primer3 software [37] was used to generate PCR primers based on the consensus sequence of any incomplete segments. PCR products were amplified using Phusion DNA polymerase and sequenced by Sanger sequencing to fill gaps that could not be completed using the metagenomic data alone. The resulting Sanger-generated sequences were then aligned to their incomplete consensus sequence and an updated consensus was called. Rotavirus consensus sequences were extracted from the alignment and genotyped using the RotaC classification tool (http://rotac.regatools.be). Phylogenies were created with sample 14 sequences and the most homologous genotypes identified by BLASTn in GenBank after removal of duplicate sequences from the same strains. Nucleotide alignments were carried out using ClustalOmega (https://www.ebi.ac.uk/Tools/msa/clustalo/) then refined in SeaView v4 [38] using amino acid homologies. Phylogenetic trees were reconstructed using maximum likelihood in IQ-TREE v1.6.11 [39] using model selection [40], a more thorough nearest neighbour interchange search ('-allnni'), and 1000 iterations of the ultrafast bootstrap approximation (-bb 1000) [41]. The resulting trees were visualised using ggtree [42] in R v3.5.1 [43].

\footnotetext{
Abbreviations

BLASTn: Basic local alignment search tool for nucleotides; CDNA: Copy DNA; DNA: Deoxyribonucleic acid; NCBI: National Center for Biotechnology Information; NSP: Non-structural protein; PCR: Polymerase chain reaction; qRT-PCR: Quantitative reverse transcription polymerase chain reaction; RefSeq: Reference sequence; RNA: Ribonucleic acid; RT-PCR: Reverse transcription polymerase chain reaction; RVA: Group A rotavirus; SISPART: Sequence-independent single-primer amplification and reverse transcription; VP: Virion protein
}

\section{Acknowledgements}

We thank Prof. Simon Frost for his advice and assistance with the construction of the phylogenetic trees. 


\section{Authors' contributions}

SS made CDNAs for sequencing and analysed the returned sequence data. $\mathrm{OQ}$ planned the project with the help of $\mathrm{BB}$, collected samples and performed the antigen and initial NSP3 RT-PCR tests. MA and SA collected and prepared samples. BW performed NSP3 and VP6 RT-PCR tests, purified, sequenced and analysed the VP6 product. IK and SG made the metagenomic sequencing libraries, performed the Illumina sequencing and helped with initial analysis. BB helped in project design and the analysis of data. All authors read and approved the final manuscript.

\section{Funding}

This work was funded by the Cambridge-Africa Alborada Research Fund through a CAPREX Fellowship to Dr. Osbourne Quaye.

\section{Availability of data and materials}

Accession numbers in GenBank for the sample 14 rotavirus sequences are: MN102365-MN102375.

\section{Ethics approval and consent to participate}

The study was conducted in accordance with the guidelines provided by the Animal Experimentation Department of the Noguchi Memorial Institute for Medical Research, an internationally acclaimed research facility in Ghana.

\section{Consent for publication}

not applicable.

\section{Competing interests}

The authors declare that they have no competing interests.

\section{Author details}

'Department of Veterinary Medicine, University of Cambridge, Cambridge, UK. ${ }^{2}$ West African Centre for Cell Biology of Infectious Pathogens (WACCBIP), Department of Biochemistry, Cell and Molecular Biology, University of Ghana, Volta Road, P. O. Box LG 54, Legon, Accra, Ghana.

Received: 30 August 2019 Accepted: 25 December 2019

Published online: 10 January 2020

\section{References}

1. Parashar UD, Nelson EA, Kang G. Diagnosis, management, and prevention of rotavirus gastroenteritis in children. BMJ. 2013;347:f7204.

2. Luchs A, Timenetsky MC. Group A rotavirus gastroenteritis: post-vaccine era, genotypes and zoonotic transmission. Einstein (Sao Paulo). 2016; 14(2):278-87.

3. Matthijnssens J, Ciarlet M, Heiman E, Arijs I, Delbeke T, McDonald SM, et al. Full genome-based classification of rotaviruses reveals a common origin between human Wa-like and porcine rotavirus strains and human DS-1-like and bovine rotavirus strains. J Virol. 2008:82(7):3204-19.

4. Theuns S, Heylen E, Zeller M, Roukaerts ID, Desmarets LM, Van Ranst M, et al. Complete genome characterization of recent and ancient Belgian pig group A rotaviruses and assessment of their evolutionary relationship with human rotaviruses. J Virol. 2015;89(2):1043-57.

5. Matthijnssens J, Van Ranst M. Genotype constellation and evolution of group A rotaviruses infecting humans. Curr Opin Virol. 2012;2(4):426-33.

6. Matthijnssens J, Ciarlet M, McDonald SM, Attoui H, Banyai K, Brister JR, et al. Uniformity of rotavirus strain nomenclature proposed by the rotavirus classification working group (RCWG). Arch Virol. 2011;156(8):1397-413.

7. Valiakos G, Chatzopoulos DC, Tsokana CN. Interspecies transmission of rotaviruses among ruminants, dogs and humans: current facts and remarks. J Hell Vet Med Soc. 2018;68(2):123-30.

8. Maes P, Matthijnssens J, Rahman M, Van Ranst M. RotaC: a web-based tool for the complete genome classification of group A rotaviruses. BMC Microbiol. 2009:9:238.

9. Li DD, Duan ZJ, Zhang Q, Liu N, Xie ZP, Jiang B, et al. Molecular characterization of unusual human G5P[6] rotaviruses identified in China. J Clin Virol. 2008:42(2):141-8.

10. Wu FT, Banyai K, Jiang B, Liu LT, Marton S, Huang YC, et al. Novel G9 rotavirus strains co-circulate in children and pigs, Taiwan. Sci Rep. 2017;7: 40731.

11. Papp H, Borzak R, Farkas S, Kisfali P, Lengyel G, Molnar P, et al. Zoonotic transmission of reassortant porcine G4P[6] rotaviruses in Hungarian pediatric patients identified sporadically over a 15 year period. Infect Genet Evol. 2013;19:71-80.

12. Huang JA, Nagesha HS, Holmes IH. Comparative sequence analysis of VP4S from five Australian porcine rotaviruses: implication of an apparent new $\mathrm{P}$ type. Virology. 1993;196(1):319-27.

13. Park JG, Alfajaro MM, Cho EH, Kim JY, Soliman M, Baek YB, et al. Development of a live attenuated trivalent porcine rotavirus A vaccine against disease caused by recent strains most prevalent in South Korea. Vet Res. 2019;50(1):2.

14. Guo L, Yan Q, Yang S, Wang C, Chen S, Yang X, et al. Full genome sequence of giant panda rotavirus strain CH-1. Genome Announc. 2013;1 (1): e00241.

15. Kaneko M, Do LP, Doan YH, Nakagomi T, Gauchan P, Agbemabiese CA, et al. Porcine-like G3P[6] and G4P[6] rotavirus A strains detected from children with diarrhoea in Vietnam. Arch Virol. 2018;163(8):2261-3.

16. Phan MVT, Anh PH, Cuong NV, Munnink BBO, van der Hoek L, My PT, et al. Unbiased whole-genome deep sequencing of human and porcine stool samples reveals circulation of multiple groups of rotaviruses and a putative zoonotic infection. Virus Evol. 2016;2(2):vew027.

17. Zeller M, Heylen E, De Coster S, Van Ranst M, Matthijnssens J. Full genome characterization of a porcine-like human G9P[6] rotavirus strain isolated from an infant in Belgium. Infect Genet Evol. 2012;12(7):1492-500.

18. Heylen E, Batoko Likele B, Zeller M, Stevens S, De Coster S, Conceicao-Neto $\mathrm{N}$, et al. Rotavirus surveillance in Kisangani, the Democratic Republic of the Congo, reveals a high number of unusual genotypes and gene segments of animal origin in non-vaccinated symptomatic children. PLoS One. 2014;9(6): e100953.

19. Shi H, Chen J, Li H, Sun D, Wang C, Feng L. Molecular characterization of a rare G9P[23] porcine rotavirus isolate from China. Arch Virol. 2012;157(10): 1897-903.

20. Matthijnssens J, Rahman M, Ciarlet M, Zeller M, Heylen E, Nakagomi T, et al. Reassortment of human rotavirus gene segments into G11 rotavirus strains. Emerg Infect Dis. 2010;16(4):625-30.

21. Do LP, Kaneko M, Nakagomi T, Gauchan P, Agbemabiese CA, Dang AD, et al. Molecular epidemiology of rotavirus $A$, causing acute gastroenteritis hospitalizations among children in Nha Trang, Vietnam, 2007-2008: identification of rare G9P[19] and G10P[14] strains. J Med Virol. 2017;89(4): 621-31

22. Park JG, Kim DS, Matthijnssens J, Kwon HJ, Zeller M, Alfajaro MM, et al. Comparison of pathogenicities and nucleotide changes between porcine and bovine reassortant rotavirus strains possessing the same genotype constellation in piglets and calves. Vet Microbiol. 2014:172(1-2):51-62.

23. Okitsu S, Khamrin P, Thongprachum A, Kongkaew A, Maneekarn N, Mizuguchi M, et al. Whole-genomic analysis of G3P[23], G9P[23] and G3P[13] rotavirus strains isolated from piglets with diarrhea in Thailand, 2006-2008. Infect Genet Evol. 2013;18:74-86

24. Monini M, Zaccaria G, laniro G, Lavazza A, Vaccari G, Ruggeri FM. Full-length genomic analysis of porcine rotavirus strains isolated from pigs with diarrhea in northern Italy. Infect Genet Evol. 2014;25:4-13.

25. Heylen E, Zeller M, Ciarlet M, Lawrence J, Steele D, Van Ranst M, et al. Comparative analysis of pentavalent rotavirus vaccine strains and $\mathrm{G} 8$ rotaviruses identified during vaccine trial in Africa. Sci Rep. 2015;5:14658.

26. Amimo JO, Junga JO, Ogara WO, Vlasova AN, Njahira MN, Maina S, et al. Detection and genetic characterization of porcine group A rotaviruses in asymptomatic pigs in smallholder farms in East Africa: predominance of P[8] genotype resembling human strains. Vet Microbiol. 2015;175(2-4):195-210.

27. Martel-Paradis O, Laurin MA, Martella V, Sohal JS, L'Homme Y. Full-length genome analysis of G2, G9 and G11 porcine group a rotaviruses. Vet Microbiol. 2013:162(1):94-102.

28. Nyaga MM, Jere KC, Esona MD, Seheri ML, Stucker KM, Halpin RA, et al. Whole genome detection of rotavirus mixed infections in human, porcine and bovine samples co-infected with various rotavirus strains collected from sub-Saharan Africa. Infect Genet Evol. 2015;31:321-34.

29. Lartey BL, Damanka S, Dennis FE, Enweronu-Laryea CC, Addo-Yobo E, Ansong D, et al. Rotavirus strain distribution in Ghana pre- and postrotavirus vaccine introduction. Vaccine. 2018;36(47):7238-42.

30. Esona MD, Geyer A, Banyai K, Page N, Aminu M, Armah GE, et al. Novel human rotavirus genotype G5P[7] from child with diarrhea, Cameroon. Emerg Infect Dis. 2009;15(1):83-6.

31. Gentsch JR, Laird AR, Bielfelt B, Griffin DD, Banyai K, Ramachandran M, et al. Serotype diversity and reassortment between human and animal rotavirus 
strains: implications for rotavirus vaccine programs. J Infect Dis. 2005; 192(Suppl 1):S146-59.

32. Zeng SQ, Halkosalo A, Salminen M, Szakal ED, Puustinen L, Vesikari T. Onestep quantitative RT-PCR for the detection of rotavirus in acute gastroenteritis. J Virol Methods. 2008;153(2):238-40.

33. Iturriza Gomara M, Wong C, Blome S, Desselberger U, Gray J. Molecular characterization of VP6 genes of human rotavirus isolates: correlation of genogroups with subgroups and evidence of independent segregation. J Virol. 2002;76(13):6596-601.

34. Djikeng A, Halpin R, Kuzmickas R, Depasse J, Feldblyum J, Sengamalay N, et al. Viral genome sequencing by random priming methods. BMC Genomics. 2008;9:5.

35. Brister JR, Ako-Adjei D, Bao Y, Blinkova O. NCBI viral genomes resource. Nucleic Acids Res. 2015;43(Database issue):D571-7.

36. Zhang Z, Schwartz S, Wagner L, Miller W. A greedy algorithm for aligning DNA sequences. J Comput Biol. 2000;7(1-2):203-14.

37. Untergasser A, Cutcutache I, Koressaar T, Ye J, Faircloth BC, Remm M, et al. Primer3--new capabilities and interfaces. Nucleic Acids Res. 2012;40(15):e115.

38. Gouy M, Guindon S, Gascuel O. SeaView version 4: a multiplatform graphical user interface for sequence alignment and phylogenetic tree building. Mol Biol Evol. 2010;27(2):221-4.

39. Nguyen LT, Schmidt HA, von Haeseler A, Minh BQ. IQ-TREE: a fast and effective stochastic algorithm for estimating maximum-likelihood phylogenies. Mol Biol Evol. 2015;32(1):268-74.

40. Kalyaanamoorthy S, Minh BQ, Wong TKF, von Haeseler A, Jermiin LS. ModelFinder: fast model selection for accurate phylogenetic estimates. Nat Methods. 2017;14(6):587-9.

41. Minh BQ, Nguyen MA, von Haeseler A. Ultrafast approximation for phylogenetic bootstrap. Mol Biol Evol. 2013;30(5):1188-95.

42. Yu G, Smith DK, Zhu H, Guan Y, Lam TT-Y. ggtree: an r package for visualization and annotation of phylogenetic trees with their covariates and other associated data. Methods Ecol Evol. 2017;8(1):28-36.

43. R: A Language and Environment for Statistical Computing. R foundation for statistical computing Vienna Austria. 2016. Available from: http://www.rproject.org/.

\section{Publisher's Note}

Springer Nature remains neutral with regard to jurisdictional claims in published maps and institutional affiliations.

Ready to submit your research? Choose BMC and benefit from:

- fast, convenient online submission

- thorough peer review by experienced researchers in your field

- rapid publication on acceptance

- support for research data, including large and complex data types

- gold Open Access which fosters wider collaboration and increased citations

- maximum visibility for your research: over $100 \mathrm{M}$ website views per year

At $\mathrm{BMC}$, research is always in progress.

Learn more biomedcentral.com/submissions 